http://jmscr.igmpublication.org/home/ ISSN (e)-2347-176x ISSN (p) 2455-0450 crossref DOI: https://dx.doi.org/10.18535/jmscr/v8i11.55

\title{
Bacteriological profile and sensitivity pattern in neonatal sepsis in tertiary care centre in Bareilly
}

Authors

\author{
Niraj Kumar ${ }^{1}$, Alka Bhambri', Vedika A Bhat ${ }^{3}$ \\ ${ }^{1}$ Junior Resident, ${ }^{2}$ Professor and Head, ${ }^{3}$ Assistant Professor \\ ${ }^{1,2,3}$ Department of Pediatrics, Rohilkhand Medical College and Hospital, Bareilly, Utter Pradesh
}

\begin{abstract}
Objective: To determine the Bacteriological Profile and Sensitivity Pattern in Neonatal Sepsis in the Nursery of a Tertiary Care Centre in Bareilly.

Method: A prospective observational study was conducted in the Department of Pediatrics, Rohilkhand Medical College and Hospital, Bareilly, over a period of one year (November2018-October 2019) on 140 patients, after getting clearance from the ethical Committee. All babies were admitted in NICU with risk factors or clinical features of neonatal sepsis or those evaluated for sepsis during their admission period, were included in the study, after taking written consent from their parents. A detailed history and thorough examination were done of all babies enrolled and their sepsis screen was sent.

Results: The sepsis screen analysis of all the enrolled patients showed that, out of all sepsis positive cases, $30 \%$ cases had a gram-positive infection while $70 \%$ cases had a gram-negative infection. $40 \%$ cases of all Gram-positive sepsis patients had Staphylococcus aureus infection, while $42 \%$ cases of Gramnegative sepsis patients had Klebsiella pneumoniae infection.

It was observed that $>50 \%$ Gram positive organisms were sensitive to Meropenem, Piperacillin + Tazobactam, Amikacin and Vancomycin. While $>50 \%$ Gram negative organisms were sensitive to Meropenem and Piperacillin + Tazobactam.

Conclusion: Thus, it can be concluded from the data that an empirical antibiotic therapy of Piperacillin + Tazobactam and Amikacin would be most efficacious in our set up as first line antibiotics rather than the combination of Cefotaxime and Amikacin which were being used up till now.
\end{abstract}

\section{Introduction}

In spite of recent advances in health care system, sepsis is still one of the major causes of morbidity and mortality in neonates worldwide. Globally, more than $40 \%$ of under-five deaths occur in the neonatal period, resulting in 3.1 million newborn deaths each year. ${ }^{1}$ Sepsis is more common in developing countries when compared with developed countries. Studies have recorded an incidence of neonatal sepsis between 11 -
24.5/1000 live births in some Asian countries. ${ }^{2}$ The Infant Mortality Rate in India is $40.5 / 1000$ live births as per the 2016 CIA World Fact book. In India too, sepsis continues to be a major cause of neonatal mortality. As per National Neonatal Perinatal Database 2002-2003, the incidence of neonatal sepsis in India was 30/1000 live birth. ${ }^{3}$ Some other population-based studies have reported that, in rural India, clinical sepsis rates ranging from 49 to $170 / 1000$ live births. ${ }^{4}$ 
Incidence has not changed much over the past decade, and the mortality due to sepsis is between $30-65 \% .^{5}$ Early use of empirical antibiotic foe the treatment of suspected neonatal septicemia is the standard practice. The spectrum of organisms that cause neonatal septicemia varies in different countries, and sometimes changes from one centre to another within the same country. The pathogens most often implicated in neonatal sepsis in developing countries differ from those seen in developed countries. Hence, the need of this study, to define first line empirical antibiotic therapy at our centre.

Neonatal sepsis is usually caused by a variety of Gram-positive as well as Gram-negative bacteria, and sometimes yeasts. Overall, Gram-negative organisms are more common and are mainly represented by Klebsiella, Escherichia coli, Pseudomonas, and Salmonella. Of the Grampositive organisms, Staphylococcus aureus, Coagulase negative staphylococci (CONS), Streptococcus pneumoniae, and S. pyogenes are most commonly isolated. ${ }^{6}$ Early diagnosis and appropriate therapy of septicemia is of utmost importance to prevent morbidity and mortality.

\section{Materials and Methods}

The study was conducted in the NICU of the Department of Pediatrics, Rohilkhand Medical College and Hospital, Bareilly, which is a tertiary care centre.

This prospective observational study was conducted over a period of one year, from November 2018 to October 2019 on 140 babies, after taking ethical clearance from the institutional ethical committee. All babies admitted in NICU or Nursery in the Department of Pediatrics with risk factors or clinical features of neonatal sepsis or babies who required evaluation for sepsis during the period of stay in the Nursery were include in the study. Neonates with gross congenital malformations, severe cardiac abnormalities, history of perinatal asphyxia, severe intracranial haemorrhage or respiratory distress syndrome and neonates taken away against medical advice
(LAMA) before being investigated or where the parents were not willing to enrol their babies in the study, were excluded from the study

After taking a written consent from all potentially eligible parents a detailed history and physical examination was performed and recorded. Patients were investigated and treatment was initiated. Cases were followed up till they were discharged, expired or left against medical advice.

All neonates evaluated for sepsis had a blood culture (in automated BacT/ALERT 3D pediatric blood culture bottle - bio Meriux) and a sepsis screen done. Antimicrobial susceptibility testing was performed against relevant antibiotics and the data analysed (using Statistical Package for Social Sciences, version 23 - SPSS Inc., Chicago, IL).

\section{Results}

A total of 156 neonates were enrolled in the study of which 16 were excluded, as they did not meet the inclusion criteria. Results of 140 patients were analysed. Baseline characteristics of the study population are given in Table-1.

Table 1: Base line characteristics

\begin{tabular}{|l|c|c|}
\hline Characteristics & & Number (\%) \\
\hline \multirow{2}{*}{ Age } & $0-72 \mathrm{hrs}$ & $49(35)$ \\
\cline { 2 - 3 } & $72 \mathrm{hrs}-28$ days & $91(65)$ \\
\hline \multirow{2}{*}{$\begin{array}{l}\text { Socio-economic } \\
\text { status }\end{array}$} & M:F & $76: 64(54: 45)$ \\
\hline \multirow{4}{*}{ Gestation } & Upper Middle & $84(60)$ \\
\hline \multirow{5}{*}{ Birth Weight } & Term & $56(40)$ \\
\cline { 2 - 3 } & Preterm & $46(33)$ \\
\cline { 2 - 3 } & LBW $(1.5-2.5 \mathrm{~kg})$ & $56(67)$ \\
\cline { 2 - 3 } & VLBW $(1.0-1.5 \mathrm{~kg})$ & $68(30)$ \\
\cline { 2 - 3 } & ELBW (<1.0 kg) & $6(13)$ \\
\cline { 2 - 3 } & Not Known & $6(4)$ \\
\hline Mode of delivery & Vaginal & $92(66)$ \\
\cline { 2 - 3 } & Caeserian section & $48(34)$ \\
\hline Place of delivery & Home & $40(28)$ \\
\cline { 2 - 3 } & Hospital (Inborn) & $36(26)$ \\
\cline { 2 - 3 } & Hospital (Outborn) & $64(46)$ \\
\hline
\end{tabular}

In our study, it was found that positive blood culture was seen in $82(58.57 \%)$ cases. However, $58(41.43 \%)$ neonates were clinically suspected of having sepsis and had a negative blood culture. $30 \%$ cases of all babies having culture positive sepsis, had a gram-positive infection while $70 \%$ had a gram-negative infection. Out of Gram- 
positive sepsis patients, the predominant organism isolated was Staphylococcus aureus (40\%) followed by Coagulase Negative Staphylococcus (24\%), Enterococci (20\%)and Group B Streptococcus (16\%). Out of those having Gram negative sepsis, the predominant organism isolate was Klebsiella pneumoniae $(42.10 \%)$ followed by Escherichia coli (24.56\%), Enterobacter (19.30\%) and Pseudomonas (14.04\%). On further analysis, it was observed that, the sensitivity pattern of $>50 \%$ patients having Gram positive infection were sensitive to Vancomycin, Meropenem, Piperacillin + Tazobactam and Amikacin. More than $50 \%$ patients with Gram negative infection were sensitive to Meropenem and Piperacillin + Tazobactam (Table- 2, 3).

Table 2: Sensitivity pattern of Gram-Positive Organisms isolated N=25 (\%)

\begin{tabular}{|c|c|c|c|c|}
\hline Antibiotics & $\begin{array}{c}\text { Staph. aureus } \\
\mathrm{N}=10(\%)\end{array}$ & $\begin{array}{c}\text { Coagulase negative } \\
\text { Staph. } N=6(\%)\end{array}$ & $\begin{array}{c}\text { Enterococci } \\
N=5(\%)\end{array}$ & $\begin{array}{c}\text { Group B Streptococcus } \\
\mathrm{N}=4(\%) \\
\end{array}$ \\
\hline Vancomycin & $10(100)$ & $6(100)$ & $5(100)$ & $4(100)$ \\
\hline Meropenem & $9(90)$ & $3(50)$ & $4(80)$ & $2(50)$ \\
\hline $\begin{array}{l}\text { Piperacillin }+ \\
\text { Tazobactam }\end{array}$ & $7(70)$ & $2(33.3)$ & $3(60)$ & $3(75)$ \\
\hline Amikacin & $6(60)$ & $4(67.7)$ & $4(80)$ & $2(50)$ \\
\hline Cefotaxime & $4(40)$ & $1(16.7)$ & $2(40)$ & $1(25)$ \\
\hline $\begin{array}{l}\text { Cefoparazone } \\
+ \text { Sulbactam }\end{array}$ & $3(30)$ & $1(16.7)$ & $1(20)$ & $0(0)$ \\
\hline Gentamycin & $2(20)$ & $1(16.7)$ & $1(20)$ & $0(0)$ \\
\hline Ceftazidime & $1(10)$ & $1(16.7)$ & $1(20)$ & $1(25)$ \\
\hline Ampicillin & $1(10)$ & $1(16.7)$ & $1(20)$ & $0(0)$ \\
\hline
\end{tabular}

Table 3: Sensitivity pattern of Gram-Negative Organisms isolated N= 57 (\%)

\begin{tabular}{|c|c|c|c|c|}
\hline Antibiotics & $\begin{array}{c}\text { Klebsiella } \\
\text { pneumoniae } \\
\mathrm{N}=\mathbf{2 4}(\%)\end{array}$ & $\begin{array}{l}\text { Escherichia coli } \\
\mathrm{N}=14(\%)\end{array}$ & $\begin{array}{c}\text { Enterobacter } \\
\mathrm{N}=11(\%)\end{array}$ & $\begin{array}{c}\text { Pseudomonas } \\
\mathrm{N}=\mathbf{8}(\%)\end{array}$ \\
\hline Meropenem & $22(91.7)$ & $10(71.4)$ & $7(63.6)$ & $7(87.5)$ \\
\hline $\begin{array}{l}\text { Piperacillin } \\
\text { Tazobactam }\end{array}$ & $16(66.7)$ & $9(64.3)$ & $6(54.5)$ & $5(62.5)$ \\
\hline Ceftazidime & $13(54.2)$ & $7(50.0)$ & $4(36.4)$ & $4(50)$ \\
\hline $\begin{array}{l}\text { Cefoparazone + } \\
\text { Sulbactam }\end{array}$ & $11(45.8)$ & $5(35.7)$ & $3(27.3)$ & $3(37.5)$ \\
\hline Cefotaxime & $10(41.7)$ & $4(28.6)$ & $2(18.2)$ & $3(37.5)$ \\
\hline Amikacin & $9(37.5)$ & $3(21.4)$ & $2(18.2)$ & $2(25)$ \\
\hline Gentamycin & $2(8.3)$ & $2(14.3)$ & $1(9.1)$ & $1(12.5)$ \\
\hline Ampicillin & $1(4.2)$ & $1(7.1)$ & $1(9.1)$ & $1(12.5)$ \\
\hline
\end{tabular}

\section{Discussion}

In neonates, positive blood culture for aerobic organisms were seen to vary from $25 \%$ to $60 \%$. In our study out of 140 cases of neonatal sepsis $58.57 \%$ (82) were culture positive. Among the culture positive cases majority were gram negative, $70 \%$ (57 cases), followed by gram positive cases, $30 \%$ ( 25 cases). Jonnala RNR et $\mathrm{al}^{7}$ observed that $57.1 \%$ cases (48) were culture positive and among the culture positive cases majority were gram negative (37 cases $-77.08 \%$ ) followed by gram positive ( 8 cases $-16.66 \%$ ) and fungi ( 3 cases $-6.2 \%$ ) which is comparable to our study.

In our study positive blood culture values were similar to the studies done by Sharma et $\mathrm{al}^{8}$, Jain et $\mathrm{al}^{9}$, Y R Khinchi et $\mathrm{al}^{10}(52.3 \%)$ and Amru $\mathrm{R}^{11}(62 \%)$.

In our study, Gram-negative and Gram-positive septicemia was encountered in $70 \%$ and $30 \%$ of the culture-positive cases respectively, which is comparable to a study conducted by Agnihotri et al, ${ }^{12}$ which reported that Gram-negative and Gram-positive organisms were responsible for 
$59 \%$ and $41 \%$ of the septicemia cases, respectively. The isolation rate of bacteria in our study is also comparable to the rates reported by A S M Nawshad et al $^{13}$ (Gram negative $73 \%$, gram positive $27 \%$ ). Studies by other researchers like Manucha et al, ${ }^{14}$ Simiyu et al, ${ }^{15}$ Anwer et al, ${ }^{16}$ Milledge et al, ${ }^{17}$ Kapoor et al ${ }^{18}$ and Movahedian et $\mathrm{al},{ }^{18}$ also showed that gram negative bacteria were responsible in most of neonatal sepsis cases.

The pathogens most often encountered in neonatal sepsis in developing countries differ from those seen in developed countries. In our study, of all patients having Gram positive sepsis $40 \%$ had Staphylococcus aureus, while in those having Gram negative sepsis $42 \%$ had Klebsiella infection. The report of the National Neonatal Perinatal database showed Klebsiella as the predominant $(29 \%)$ pathogen. $^{20}$ Similar findings have been reported in previous studies by Zakariya et $\mathrm{al}^{21}(66 \%)$ and Afroza et $\mathrm{al}^{22}(64 \%)$.

In the studies undertaken in other developing countries Gram negative organisms were common and Klebsiella and Enterobacter were the most frequently occurring organisms. ${ }^{18,19}$ whereas Gram positive cocci are the most common bacterial isolates in the developed countries. In United States, Group B Streptococci was reported as the most common pathogen in term infants by National Institute of Child Health Development.

In our study most of the Gram-Negative Organisms were sensitive to Meropenem followed by, in decreasing order by Piperacillin + Tazobactam, Cefoperazone + Sulbactam, Ceftazidime, Cefotaxime and Amikacin. Most of the Gram-Positive Organisms were sensitive to Vancomycin followed by Meropenem, Piperacillin + Tazobactam, Amikacin, Cefotaxime and Cefoperazone + Sulbactam. In a study from Sydney Neonatal Infection Surveillance, they have mentioned that all Gram-Negative Bacteria were susceptible to Gentamicin and Third Generation Cephalosporin (Levine et al). ${ }^{23}$ Waheed et $\mathrm{al}^{24}$ found Cefotaxime as the most efficacious drug with $80 \%$ sensitivity to Klebsiella, $70 \%$ to Staphylococcus aureus and $65 \%$ to Escherichia coli. Anwer et $\mathrm{al}^{16}$ found Amikacin to be the most effective antibacterial with an efficacy of about $90-100 \%$, then Cefotaxime with a sensitivity of 84-89\%. Ampicillin had the least sensitivity i.e. less than $20 \%$. Mokuolu et $\mathrm{al}^{25}$ found that $94 \%$ of the organisms were sensitive to Azithromycin followed by Streptomycin (77.8\%), Gentamicin $(73.3 \%)$ and Ampicillin + Sulbactam (69.2\%). The common pathogens in this study were Staphylococcus aureus, Coagulase negative staphylococcus albus, Klebsiella species and unclassified Coliforms.

Ellabib et $\mathrm{al}^{26}$ found Enterobacteriaceae to be most common (Serratia, Klebsiella and Enterobacter species) followed by Coagulase negative and positive staphylococci. Low resistance was found to Imipenem, Ciprofloxacin and Piperacillin + Tazobactam, while all Staphylococci were sensitive to Vancomycin. Shresta et $\mathrm{al}^{27}$ found highest resistance to Ampicillin (91.94\%) and least to Chloramphenicol (94.84\%).

\section{Conclusion}

Thus, we can conclude from our data that an empirical antibiotic therapy of Piperacillin + Tazobactam and Amikacin would be most efficacious in our set up as first line antibiotics rather than, the combination of Cefotaxime and Amikacin which were being used till now.

\section{References}

1. UNICEF, WHO, The World Bank, and The United Nations, Levels and Trends in Child Mortality, UNICEF, New York, NY, USA,2011.

2. Wu Jh, Chen CY, Tsao PN, Hsieh WS and Chou HC. "Neonatal sepsis: a 6-year analysis in a neonatal care unit in Taiwan," Pediatrics and Neonatology, 2009; 50(3): 88-95.

3. National Neonatology Forum NNPD Network. National Neonatal-Perinatal Database: Report for 2002-2003. New 
Delhi: National Neonatology Forum NNPD Network;2005.

4. Thaver D, Zaidi AK. Burden of neonatal infections in developing countries: A review of evidence from community-based studies. Pediatr Infect Dis J2009;28:3-9.

5. Mathur NB. Neonatal sepsis. Indian Pediatr1996;33:663-74.

6. Shah AJ, Mulla SA, Revdiwala SB. Neonatal sepsis: High antibiotic resistance of the bacterial pathogens in a neonatal intensive care unit of a tertiary care hospital. J ClinNeonatol2012;1:72-5.

7. Jonnala RNR, Eluzai Z, Rao NS. Clinical and Laboratory Profile of Neonatal Sepsis. International Journal of Medical and Applied Sciences,2013;2(4):319-31.

8. Sharma PP, Halder D, Dutta AK, Dutta R, Bhatnagar S, Bali A, et al. Bacteriological profile of neonatal septicemia. Indian Pediatr,1987;24:1011-7.

9. Jain NK, Jain VM, Maheshwari S. Clinical profile neonatal sepsis. Kathmandu University Medical Journal,2003;1:117120.

10. Khinchi1 Y R, Anit K, Satish Y. Profile of Neonatal sepsis. Journal of College of Medical Sciences-Nepal,2010;6(2):1-6.

11. Amru R. Clinical and bacteriological profile of Neonatal sepsis.MD Thesis. Osmania Medical College, Hyderabad; 1997.

12. Agnihotri N, Kaistha N, Gupta V. Antimicrobial susceptibility of isolates from neonatal septicemia. Jpn J Infect Dis, 2004; 57:273-5.

13. A S M Nawshad Uddin, chowdhury M A K Azad, Hoque Mahbul and Gray L. Clinical and Bacteriological Profile of Neonatal Septicemia in a Tertiary level Pediatric Hospital in Bangladesh. Indian Pediatr,2002;39:1034-1039.

14. Manucha V, Rusia U, Sikka M, Faridi MM, Madan N. Utility of hematological parameter and $\mathrm{C}$-reactive protein in the detection of neonatal sepsis. J Paediatr Child Health,2002;38:459-464.

15. Simiyu DE. Neonatal septicaemia in low birth weight infants at Kenyatta National Hospital, Nairobi. East Afr Med J,2005; 82:148-52.

16. Anwer SK, Mustafa S, Pariyani S, Ashraf S, Taufiq KM. Neonatal sepsis: an etiologic study. J Pak Med Assoc, 2000;50:91-94.

17. Milledge J, Calis JC, Graham SM, Phiri A, Wilson LK, Soko D, Mbvwinji M, Walsh AL, Rogerson SR, Molyneux ME, Molyneux EM. Aetiology of neonatal sepsis in Blantyre, Malawi: 1996-2001. Ann Trop Paediatr,2005;25:101-10.

18. Kapoor L, Randhawa VS, Deb M. Microbiological profile of neonatal septicemia in a pediatric care hospital in Delhi.JCommun Dis,2005;37:227-32.

19. Movahedian AH, Moniri R, Mosayebi Z. Bacterial Culture of Neonatal Sepsis. Iranian J Publ Health,2006;35:84-89.

20. National Neonatology Forum NNPD Network. National Neonatal-Perinatal Database: Report for 2002-2003. New Delhi: National Neonatology Forum NNPD Network;2005.

21. Zakariya BP. Neonatal sepsis in a tertiary care hospital in South India: Bacteriological profile and antibiotic sensitivity pattern. Indian $\mathbf{J}$ Pediatr, 2011;78(4):413-7.

22. Afroza S. Neonatal sepsis-- a global problem: an overview. Mymensingh Med J, 2006;15:108-14.

23. Levine EM, Ghai V, Barton JJ, Strom CM. Intrapartum antibiotics prophylaxis increases of gram negative neonatal sepsis. Infec Dis Obstet Gynaeco,1999;17:210213.

24. Waheed M, Laeeq A, Maqbool S. The etiology of neonatal sepsis and patterns of antibiotic resistance. J Coll Physicians Surg Pak,2003;13:449-52. 
25. Mokuolu AO, Jiya N, Adsiyun OO.

Neonatal septicemia in Ilorin: bacterial pathogens and antibiotic sensitivity pattern. Afr J Med Sci, 2002;31:127-30.

26. Ellabib MS, Ordonez A, Ramali A, Walli A, Benayad T, Shebrlo H. Changing pattern of neonatal bacteremia. Microbiology and antibiotic resistance. Saudi Med J,2004;25:1951-6.

27. Shrestha B, Pokhrel BM, Mohapatra TM. Antibiotic susceptibility pattern of nosocomial isolates of staphylococcus aureus in a tertiary care hospital, Nepal. Nepal Med Assoc J,2009;48:234-8. 